\title{
A Collaborative Learning Approach And its Evaluation
}

\author{
Lucila Ishitani, Silvio J. F. Guimarães and Gisele Bruegger \\ Pontifícia Universidade Católica de Minas Gerais \\ Belo Horizonte - MG - Brazil \\ \{lucila, sjamil, gisele\}@pucminas.br
}

\begin{abstract}
The use of new technologies does not mean that the applied education model is modern. New technologies can be used in a way that follows the traditional education model, with all its deficiencies. The collaborative education model involves students in reflection, participation, and construction of their knowledge, or to collaboratively learn. This article aims to present mechanisms to stimulate collaborative learning, in present education, through the aid of virtual learning environments.
\end{abstract}

\section{Introduction}

Traditional teaching methods are being criticized, mostly because of two characteristics. The first one is that they are centered on the role of the teachers, who are considered the only ones who have knowledge and, as such, are able to transmit it. The second one is the preference for lectures, with few student-teacher or studentstudent interactions. This characteristic has the disadvantage that students remain passive, just listening, memorizing and repeating what they are supposed to learn. Thus, the traditional teaching model seems incompatible with the modern workplace, which requires people with teamwork, critical thinking and communication skills 3 6. Besides that, the concept of learning has also changed: "learning is not to receive knowledge, but to make sense of knowledge and to promote in a learner an independent mind that can inform, reflect and even challenge conventional knowledge wisdom" 3. Thus, in the new teaching model students and teachers have an active role. Knowledge is shared and built. The learning process occurs collaboratively. Each student, besides being responsible for his/her own learning, contributes to his/her classmates' learning.

One option we have to implement this new learning and teaching model is to apply information technologies and the Internet, aiming to change the ways "schools work, teachers teach, and students learn" 2. For example, an aid tool to the traditional present classes can be a Virtual Learning Environment (VLE). A VLE can be defined as a system that groups different tools and facilities, empowering

Please use the following format when citing this chapter:

Ishitani, L., Guimarães, S.J.F., Bruegger, G., 2006, in Intemational Federation for Information Processing, Volume 210 , Education for the $21^{\text {st }}$ Century-Impact of ICT and Digital Resources, eds. D. Kumar, and Tumer J., (Boston: Springer), pp. 333-337. 
learning activities through the Internet, or "a program or set of programs that operates over a network and supports users as they undertake tasks or participate in processes related to learning" 2 . Through their communication facilities, such as forums, chats and document sharing areas, "the use of the Internet and the web can help the constructivist theory because it is possible to build a Learning by Doing environment that also combines the constructivist approach and cooperative learning"6. Many published proposals consider the web and VLEs as powerful tools that offer teachers resources to change the way they work, motivating a more interactive learning process. Sala 6 proposed a group development of a database. Laffey et al 2 present a framework showing how a VLE or a Network Learning System (NLS) could be used to improve education, but they do not present any results of the proposed framework.

However, simply grouping students and using a VLE does not imply that we have modern collaborative learning $(4,5,8)$. Even applying a VLE, a teacher can be adopting a traditional teaching method. For example, there are teachers who use VLEs just to make available texts and activities for their students. The teacher is the only one responsible for transmitting information. There are no discussions, no interactions among students and no knowledge building by the students.

This paper presents an application of VLE as tools to aid existing classes. It is organized as follows. In Section 2 we present our proposal and case study results, and in Section 3, we present our conclusions and future work.

\section{A Collaborative approach with VLE}

\subsection{Learnloop}

There are many available Virtual Learning Environments, for example, Moodle, Whiteboard ${ }^{9}$ and WebCT $^{10}$. Some of them are free software. The Western Cooperative for Educational Telecommunications (WCET) presents, in its site Edutools ${ }^{11}$, a comparison among many of these VLEs. Thanks to a number of already implemented resources, five years ago the Instituto de Informática of Pontifícia Universidade Católica de Minas Gerais (PUC Minas) chose the free software Learnloop ${ }^{12}$. During the five years since adoption, many improvements were incorporated to the original version (http://www.inf.pucminas.br) 1. Presently it has been adopted by nine courses or near 4,000 graduate and post-graduate students.

\footnotetext{
${ }^{8} \mathrm{http}: / /$ moodle.org/

${ }^{9} \mathrm{http}: / /$ whiteboard.sourceforge.net/

${ }^{10} \mathrm{http}: / / \mathrm{www}$.webct.com/

${ }^{11} \mathrm{http}: / /$ www.edutools.info/course/compare/

12 http://www.learnloop.org
} 


\subsection{A collaborative proposal}

The proposal presented in this section aims to introduce students to do research and to produce a paper in group. To accomplish the proposed activities, it is important to specify a unique general theme for all students of a class. It can be divided into three main activities:

First activity: survey. During the period of a month and a half, each student must post at least one contribution per week in the class forum, in Learnloop. This contribution can be a reference to a technical paper that (s)he had selected, with at least five main ideas, or a justified criticism to a paper referenced by a classmate.

Second activity: scope definition. This activity requires that students be organized in groups. It should be completed with the aid of the Learnloop group resource. For each student group, a group is also created in Learnloop with at least three resources: messages among group members, forum and a virtual disk to share files. The objective of this activity is to develop a unique work plan per group, composed of: group organization, paper scope, paper structure and selected references.

Third activity: paper elaboration. To fulfill this activity, students continue to use Learnloop groups. Each one will be responsible for a paper section or subsection. The group leader will have to organize the paper, and (s)he will also have to write the introduction and conclusion of the paper. Because of that, (s)he does not write any other part of the paper.

\subsection{Proposal evaluation}

The proposed collaborative model was implemented in a class of 26 students, organized in six groups. The main advantage of this model is that it compels every student to participate. Although the activities must be done as a group, the grades are given individually. As the teacher can track all the students' activities in Learnloop, the following problems can be eliminated or, at least, diminished:

Students lost with the great amount of information available in the web. The forum discussion completed during the first activity contributes to the development of their critical abilities, before choosing the scope of their paper and selecting the best references for the paper they are supposed to write.

Difficulties to meet. Learnloop, as other VLEs, offers flexibility of time and space to discuss ideas.

Paper written only when the deadline is getting close. The proposed approach makes students work during all the class periods.

Students who do not collaborate. The only problem we face is that anyone can ask or pay for another to $\log$ in Learnloop with his/her username and to do his/her activities in his/her name. A solution to this problem is to apply a test or ask the students to orally present their contributions.

Plagiarism. The number of classmates or web copies diminishes, because the discussions, along with the teacher's tracking, inhibit students from just copying others works/ideas.

From our experience, we can see that even virtually, students have great difficulties in working in groups. There is no need for the teacher to remain logged 
in. The tracking could be done once in a day and (s)he can participate when necessary. But unfortunately, if the teacher keeps logged off for a long period and does not remind students of the importance of working together, students have a great tendency to stay in the traditional passive position.

Table 1 presents the number of posted contributions, during the third activity, for each group. As we can see, in spite of being almost obliged to work collaboratively, the number of student participations is kind of low. We can point to two reasons for this situation. The first one is that some contributions were very extensive, deeply evaluating all group work. The second one is that some students have much difficulty in working in a group. As we assigned some group exercises during some classes, we could observe students' attitudes. And we could observe that students who do not work well in a group virtually are the same who do not contribute presently.

Student grades were proportional to their collaboration in group work. Their grades are also summarized in Table 1. It is important to emphasize that although the work was to be done in a group, $60 \%$ of the grade was individually evaluated, considering the quality of the contributions. $40 \%$ of the grade was evaluated considering the teamwork and final paper presented by the group (cohesion and quality). There are two results that deserve explanations. The low average grade of group 3 can be justified by two low individual grades, due to light cases of plagiarism. The good grade of group 6 was a consequence of the high level contributions of two members of the group.

Table 1. Number of contributions during the third activity, considering both the students who have completed the assignment (C) and the ones who have not completed the assignment (NC). The group grades are considering only students who have completed the assignment.

\begin{tabular}{c|cc|cc|cc|ccc}
\hline \multirow{2}{*}{$\begin{array}{c}\text { Group } \\
\text { number }\end{array}$} & \multicolumn{2}{|c|}{ Group size } & \multicolumn{2}{|c|}{ Post numbers } & \multicolumn{2}{c|}{ Avg post } & \multicolumn{3}{|c}{ Grade } \\
& NC & C & NC & C & NC & C & Avg & Low & High \\
\hline 1 & 4 & 3 & 20 & 17 & 5.00 & 5.67 & 17.0 & 15.5 & 19.5 \\
2 & 4 & 3 & 13 & 11 & 3.25 & 3.67 & 10.0 & 7.0 & 14.0 \\
3 & 3 & 3 & 23 & 23 & 7.67 & 7.67 & 13.7 & 12.0 & 15.0 \\
4 & 5 & 5 & 15 & 15 & 3.00 & 3.00 & 10.0 & 6.0 & 15.5 \\
5 & 5 & 3 & 11 & 11 & 2.20 & 3.67 & 11.7 & 9.0 & 13.0 \\
6 & 5 & 5 & 18 & 18 & 3.60 & 3.60 & 14.2 & 11.0 & 19.0 \\
\hline Total & 26 & 22 & 100 & 95 & 3.85 & 4.32 & - & - & - \\
\hline
\end{tabular}

\section{Conclusions}

In this paper we presented an application model of VLEs, aiming to improve: (i) student-student and student-teacher communications through information sharing and exchange; (ii) team working; (iii) the development of critical abilities of the students; and (iv) progressive evaluation in which the teachers are able to track students' activities and can evaluate them during their development. Although the 
model was adapted to the specific activity of paper writing, it can be extended and adapted to other group activities. For example, after designing a computer system, each member could be responsible for a module, and doubts and corrections could be discussed through a forum. As future work, we propose to offer teachers tools to make easier the tracking and evaluation of students' activities.

\section{Acknowledgments}

The authors are grateful to PUC Minas (Pontificia Universidade Católica de Minas Gerais) and FAPEMIG (Fundação de Amparo à Pesquisa do Estado de Minas Gerais) for the financial support of this work.

\section{References}

1. Gisele R. Brugger, José Wilson Costa, Theldo Cruz Franqueira, and Lucila Ishitani. Um ambiente de apoio ao ensino presencial. In Anais do XIII Workshop sobre Educação em Computação, p. 2363-2370, São Leopoldo, Brasil, julho 2005.

2. James M. Laffey, Dale Musser, Herbert Remidez, and Josh Gottdenker. Networked systems for schools that learn. Communications of the ACM, 46(9):192- 200, September 2003.

3. Thao Lê. Collaborate to learn and learn to collaborate. In Proc. 7th World Conference on Computers in Education, p. 67-70, Copenhagen, Denmark, july-august 2002. ACM.

4. Noel LeJeune. Critical components for successful collaborative learning in CS1. Journal of Computing Sciences in Colleges, 19(1):275-285, October 2003.

5. Teresa Roselli, Eleonora Faggiano, Paola Plantamura, and Veronica Rossano. A wwwbased cooperative learning system and its effects on students' achievement. In Proc. Int. Conf. on Computers in Education (ICCE 2002), p. 283-287, Auckland, New Zealand, 2002.

6. Nicoletta Sala. Cooperative learning and web applications: A case study. In Proc. 19th Int. Conf. on Advanced Information Networking and Applications (AINA'05), p. 101104,2005 .

7. Friedrich Scheuermann, Nick Kearney, Ken Larsson, Rüdiger Fries, and Roxanne Toto. Designing collaborative activities in virtual environments for learning. In Proc. 5th Int. Conf. on Information Technology Based Higher Education and Training (ITHET 2004), p. 641-643, Istanbul, Turkya, 2004.

8. Karl A. Smith. Cooperative learning: Effective teamwork for engineering classrooms. In Proc. 1995 IEEE Frontiers in Education Conference, p. 2b5.13-2b5.18, 1995. 